Елена Архипова, Алевтина Старшинова

\title{
ОТ ПРОБЛЕМЫ К РЕШЕНИЮ: РИТОРИКА ДИСКУРСА СОЦИАЛЬНЫХ ПРЕДПРИНИМАТЕЛЕЙ
}

Статья является результатом исследования, посвященного анализу дискурса современных социальных предпринимателей как акторов легитимации социальных проблем общества. Базируясь на идеях конструкционистского подхода, мы рассматривали социальные проблемы не как объективную данность, существующую в обществе, а как конструкт, создаваемый людьми посредством выдвижения утверждений-требований (claim-making) изменить какую-либо ситуацию. Социальные предприниматели, являясь новыми акторами процесса выдвижения и легитимации социальных проблем, обладают высоким потенциалом не только в конструировании социальной проблемы, но также и в выработке ее эффективного решения. Эмпирической базой исследования выступили публичные выступления, интервью, а также описания проектов, представленные на официальных сайтах, крауд-платформах и в социальных сетях лидеров российского социального предпринимательства-Гузели Санжаповой и Дарьи Алексеевой. Обе предпринимательницы активно включаются в дискурс социальных проблем, формулируют утверждения-требования и продвигают их на публичных аренах. Для анализа была применена концепция Питера Ибарры и Джона Китсьюза, измеряющая дискурс социальных проблем в четырех измерениях риторики: риторических идиомах, контрриторике, лейтмотивах и стилях выдвижения утверждений-требований. Исследование показало, что при легитимации проблемы, которую выдвигают на публичную арену социальные предпринимательницы, абсолютно отсутствуют негативные и драматические риторические идиомы, такие как риторики бедствия,

Елена Борисовна Архипова-к.социол.н., доцент, кафедра социальной работы, Уральский федеральный университет, Екатеринбург, Россия. Электронная почта: e.b.arkhipova@urfu.ru

Алевтина Викторовна Старшинова- д.социол.н., профессор, кафедра социальной работы, Уральский федеральный университет, Екатеринбург, Россия. Электронная почта: a.v.starshinova@urfu.ru 
неразумности и опасности. Присутствуют риторика утраты и риторика наделения правом, которая декларирует равенство прав и возможностей всех общественных групп, но не посредством государственной помощи, a с помощью альтернативного решения, провоцирующего масштабные и устойчивые трансформации в государственной политике и гражданском обществе. Уникальность дискурса социальных предпринимателей заключается не в драматизации ситуации, а в демонстрировании и тиражировании опережающего способа поддержания социального равновесия. Эта позиция позволяет сделать вывод, что выбранные нами социальные предприниматели, согласно типологии Шэйкера Зары, выполняют роль «социальных конструкционистов», восполняющих социальные пробелы, решающих острые социальные проблемы, работающих в тех сферах и с той группой, которые остаются за пределами интересов других агентов социальной политики.

Ключевые слова: социальное предпринимательство, социальные проблемы, конструкционизм, риторика, дискурс

DOI: 10.17323/727-0634-2021-19-1-41-54

\section{Теоретическое обоснование потенциала социального предпринимательства в актуализации и решении социальных проблем}

Государственная социальная политика и социальная работа часто опираются на структурно-функциональный подход при решении социальных проблем, согласно которому социальные проблемы существуют как объективные условия в структуре общества и являются закономерным следствием состояния дисфункции. В русле данного подхода задача социологии- понять суть социальной проблемы, а задача социальной политики и социальной работы- предложить ее решение. Согласно анализу Герберта Блумера (Blumer 1971), современные меры социальной политики при этом малоэффективны, поскольку государственные институты начинают «работать» над социальной проблемой только после того, как она получит официальное признание. То есть социальная политика всегда находится на несколько шагов позади актуальности социальных проблем для целевых групп, т.к. государственные институты априори не могут реализовать оперативное решение и реагируют только тогда, когда проблема уже получила внимание в СМИ. Получается, что процесс возникновения проблемы и начало реагирования на нее государственных структур отсрочены во времени и за этот период могут произойти существенные изменения в условиях, форме и степени дисфункции.

Конструкционистский подход (Becker 1966; Spector, Kitsuse 1977; Loseke 2003; Ibarra, Kitsuse 2003; Ясавеев 2004; 2016; 2019; Бест 2007; Ибарра, Китсьюз 2007; Хилгартнер, Боск 2007; Полач 2010; Кольцова, Ясавеев 2013) рассматривает социальные проблемы не как объективную 
данность, существующую в обществе, а как конструкт, создаваемый людьми в процессе коллективного определения проблемы. Согласно теории Блумера (Blumer 1971:301), процесс конструирования включает в себя 5 стадий: (1) возникновение социальной проблемы, (2) легитимация проблемы, (3) мобилизация действий в отношении проблемы, (4) формирование официального плана действий и (5) трансформация официального плана в ходе его осуществления.

Возникновение социальной проблемы является следствием избирательного процесса идентификации и отбора неблагоприятных социальных условий, которому уделяется мало внимания среди исследователей социальных проблем. Блумер акцентирует внимание на том, что существование социальной проблемы начинается только тогда, когда общество признает, что она существует (Ibid: 301-302). Признанные в обществе проблемы («успешно» прошедшие легитимацию) конституируются в повестке дня общественного обсуждения, где становятся объектом публичной полемики. Результатом данного обсуждения является разработка официального плана действия как консенсуса взглядов и интересов различных групп. В процессе его реализации первоначальный коллективный образ проблемы может значительно трансформироваться.

Конструирование социальных проблем обычно осуществляется либо инсайдерами социальной политики- чиновниками, представителями администрации и другими заинтересованными группами, либо «аутсайдерами» социальной политики- активистами, представителями некоммерческих организаций, блогерами, социальными предпринимателями и т.п. Акторы из второй группы обычно приближены к реальному процессу жизнедеятельности социально-уязвленных целевых групп на всех этапах конструирования социальной проблемы. В рамках данной статьи мы остановимся на одном из самых новых и перспективных акторов выдвижения и легитимации общественных проблем- социальном предпринимателе.

Несмотря на то, что примеры социально-предпринимательской деятельности можно увидеть в более ранние исторические периоды, в научной литературе этот термин начал использоваться только во второй половине XX в. Одни исследователи пытались найти проблемное поле социального предпринимательства в сравнении с традиционным бизнесом, благотворительностью, общественными организациями (Salamon 1997). Другие-в поиске и описании инновационной составляющей деятельности социального предприятия в решении социальных проблем (Dees, Anderson 2006). Третьи- в гибридности коммерческой и социальной миссии предприятия (Defourny, Nyssens 2010). Социальный бизнес, стремясь получить прибыль и продвигая свои товары/ услуги (а вместе с ними и социальную миссию), неизбежно способствует легитимации выбранной им социальной проблемы. Как следствие, социальный предприниматель обладает возможностью выступить катализатором общественных изменений, которые выйдут далеко за рамки его деятельности. 
Легитимация- это социальная поддержка проблемы на аренах общественного обсуждения (СМИ, школа, общественные организации, законодательные учреждения), это выдвижение утверждений-требований (claimmaking) в попытке убедить аудиторию в существовании проблемы, в необходимости прилагать усилия для ее разрешения. Общая схема актуализации утверждений-требований выглядит следующим образом: демонстрация проблемы- объяснение причин проблемы- рекомендации о разрешении проблемы- призыв к деятельности. Джоел Бест (2007:32-34) называет эту схему «рецептом» аргументации. Каждые группы, выдвигающие свои утверждения-требования, используют разные модели аргументации в попытке убедить аудиторию в существовании определенной социальной проблемы. Например, «рецепты» проблематизации бедности могут иметь мелодраматический характер, рассматривая бедность как результат безответственности самих бедных, а могут опираться на статистические данные, демонстрирующие структурное неравенство общества. Потенциал социального предпринимательства в конструировании социальных проблем заключается в том, что оно не только актуализирует/легитимизует проблему, но также предлагает инструменты для ее преодоления, которые можно распространить на государственную социальную политику.

Многие бизнесмены ошибочно полагают, что наличие социальной цели в бизнесе автоматически сделает их социальными предпринимателями. Если исходить только из данной предпосылки, то к социальным предприятиям (даже в нашей стране) можно отнести значительное количество фирм и организаций. Однако если анализировать их деятельность и оценивать вклад в легитимацию общественных проблем, то только единицы из общего числа социальных предпринимателей реально включаются в дискурс социальных проблем, формулируют утверждения-требования и продвигают их на публичных аренах. Мы исходим из утверждения, что бизнес только в том случае является социальным, если его владелец включается в процессы актуализации и легитимации проблем, лежащих в основе социальной миссии предприятия. Только в этом случае социальный предприниматель будет являться актором социальной политики, агентом социальных изменений, а его выступления на публичных аренах можно рассматривать как форму конструирования социальных проблем.

Вышесказанное определяет цель данного исследования- выявить доминирующий контекст актуализации и легитимации социальных проблем в дискурсе социальных предпринимателей, позволяющий рассматривать успешных социальных предпринимателей как агентов социальной политики и социальных изменений. Основные исследовательские вопросы, детализирующие поставленную цель: каков характер публичных выступлений социальных предпринимателей в поддержку своих проектов, какие риторические идиомы доминируют в публичных выступлениях социальных предпринимателей, каковы наиболее распространенные лейтмотивы 
интервью и публикаций в СМИ о социальном бизнесе, каковы стратегии мобилизации действий по разрешению социальных проблем, предлагаемые социальными предпринимателями?

\section{Методология исследования и эмпирическая база}

Для анализа дискурса социальных предпринимателей, направленного на легитимацию социальных проблем и способов их решения, была применена концепция Питера Ибарры и Джона Китсьюза (Ibarra, Kitsuse 2003; Ибарра, Китсьюз 2007), которые предложили измерять дискурс социальных проблем в 4 измерениях риторики: риторических идиомах, контрриторике, лейтмотивах и стилях выдвижения утверждений-требований. Риторическая идиома- это типизация проблемы в моральном универсуме, которая присваивает статус проблеме и определяет уровень ее резонанса. Контрриторика, как правило, направлена против формата использования тех или иных символических связей в риторике оппонентов с целью противодействия конструированию проблемы. Лейтмотивы- это распространенные фразы, в краткой форме описывающие динамику типизации проблемы или реакцию на нее. Стили выдвижения утверждений-требований-это неязыковые формы подачи материала, которые определяют текстуру утверждений-требований и структурируют их восприятие (Ибарра, Китсьюз 2007: 70-71).

Риторической деконструкции были подвергнуты публичные выступления лидеров российского социального предпринимательства. Критерии отбора объектов для исследования включали в себя следующие параметры: известность, активность на публичных аренах, стаж, гендерная принадлежность. Иными словами, мы выбирали социальных предпринимателей одного пола (чтобы исключить влияние гендерной принадлежности спикеров), со стажем деятельности не менее 5 лет, принимающих активное участие в легитимации социальных проблем на публичных аренах. В итоге наш выбор был сделан в пользу Гузели Санжаповой (д. Малый Турыш, Свердловская область) и Дарьи Алексеевой (Charity Shop, г. Москва). Обе предпринимательницы активно включаются в дискурс социальных проблем, формулируют и продвигают утверждения-требования, входят в ТОП самых успешных российских социальных предпринимателей. И мы сознательно выбрали кейсы из разных регионов (столичный и провинциальный) и с разными бизнес-моделями, чтобы оценить влияние данных характеристик на специфику транслируемой риторики. Обсудим их подробнее.

В 2013 г. Гузель Санжапова организовала на семейной пасеке в отдаленной деревне Малый Турыш социальный бизнес, трудоустроив на своем предприятии местных жителей, в основном лиц пожилого возраста. Спектр выпускаемой продукции включает в себя крем-мед, карамельную продукцию, чай и прочие продукты питания, натуральную косметику, столярные изделия и текстиль. Предпринимательница изначально позицио- 
нировала свой бизнес как предприятие, направленное на спасение деревни от вымирания. В поддержку проекта Гузель Санжапова очень активно ездит по стране, проводит встречи с активистами, выступает на форумах, запускает краудфандинговые кампании. Со временем предпринимательница отошла от первоначального названия своего бизнеса-Cocco Bello Honey, сейчас в ее риторике все чаще используется название деревни- Малый Турыш. Тем самым она продвигает уже не свой бренд, а малую, отдаленную от благ цивилизации деревню, которая постепенно становится символом преодоления бедности, безысходности и деградации современного села.

Дарья Алексеева основала первый благотворительный магазин Charity Shop в 2014 г., фонд «Второе дыхание»- в 2015 г. Изначально идея бизнеса заключалась в сборе ненужных вещей, которые после сортировки и чистки продаются в благотворительном магазине по сниженным ценам. С развитием бизнеса появились и дополнительные направления: переработка ветоши/ненужных вещей, бесплатная выдача одежды через фонд «Второе дыхание», трудоустройство социально незащищенных групп (малоимущих, бывших заключенных, бездомных). Сбор вещей осуществляется через точки сбора, расположенные в разных районах г. Москвы и региональных городов, а также на территории различных организаций. Только $3 \%$ из всех собранных вещей продаются в магазине по цене в 5 раз дешевле от первоначальной стоимости, остальные $97 \%$ подвергаются сортировке, стирке и переработке. Вещи хорошего качества, но не подошедшие для розничной торговли, передаются в благотворительный фонд, остальные перерабатываются. На момент написания статьи сеть Charity Shop насчитывала 8 магазинов: 4- в Москве и 4-в регионах. Прибыль магазинов идет на деятельность благотворительного фонда и инфраструктуры сбора вещей. Переработка ветоши не приносит прибыли, но работает на экологическую миссию организации.

Таким образом, бизнес-модель Гузели Санжаповой- это локальный, провинциальный семейный бизнес, с возможностью привлечения большого числа сезонных рабочих и постоянного расширения ассортимента, развивающийся за счет харизмы и лидерских качеств владельца. Бизнес-модель Дарьи Алексеевой-глобальный столичный бизнес, работающий в рамках модели freemium (бесплатный доступ к неограниченному использованию базовых функций и платный доступ к дополнительной функциональности), ограниченный в возможностях расширения ассортимента, но привлекательный для тиражирования на условиях франчайзинга.

В ходе исследования было проанализировано 10 самых популярных интервью Санжаповой и Алексеевой, представленных в сети Интернет (отбор осуществлялся через поиск Google, в базу исследования попали первые 10 интервью для различных печатных и онлайн-изданий). Кроме этого, были проанализированы официальные интернет-сайты каждого социального бизнеса, личные страницы в социальной сети Facebook, 
а также описания краудфандинговых проектов Гузели Санжаповой на платформах Planeta и Boomstarter.

\section{Риторика социальных предпринимателей в актуализации и решении социальных проблем}

Центральный термин в риторике дискурса-это условия-категории, т.е. те термины/языковые единицы, которые используют акторы легитимации социальных проблем для оценки социальной реальности, типизации социально определяемых активностей и процессов (Ибарра, Китсьюз 2007: 63). Для Гузели Санжаповой (Г.С.) таким условием-категорией выступает «возрождение малых деревень» с акцентом на тех позитивных изменениях, которые уже произошли в ходе реализации социальной миссии бизнеса: «Производство стало локомотивом в восстановлении крохотной деревни... Я вижу, что люди планируют свое будущее в Малом Турьие... Мы действительно собираемся развивать деревню» (Г.С., Афиша Daily 2018).

Условие-категория в дискурсе Дарьи Алексеевой (Д.А.)-«экопотребление»:

Я знаю, что если бы мы собрали всю одежду в Москве, какую выбрасывают люди, то это сократило бы количество парниковых газов настолько же, сколько их производят 450 тысяч автомобилей (Д. А., Афиша Daily 2017). Это моя цель... Из магазинов, в которых что-то продается, мы превратились в полноценную экосистему... Любой бизнес можно сделать более человечным, экологичным (Д.А., Типичная Москва 2018).

При легитимации проблемы, которую выдвигают на публичную арену данные социальные предприниматели, отсутствуют негативные риторические идиомы, такие как риторика бедствия, риторика неразумности, риторика опасности. Социальные предприниматели демонстрируют нам два типа риторик: риторика утраты и риторика наделения правом,-которые можно отнести к условно положительным. Риторика утраты- это не скорбь по поводу исчезновения чего-либо, а выступление против обесценивания. Актор публичного обсуждения акцентирует внимание на том, что какой-то «уникальный» объект (небольшая самобытная деревня) в силу потери ценности (сельского образа жизни) находится под угрозой исчезновения. Ибарра и Китсьюз (2007: 75-76) в моральный словарь данной идиомы включали как положительные термины (невинность, красота, чистота, природа, наследие, культура), так и негативные (грех, загрязнение, упадок, хаос). Социальные предприниматели используют только позитивные из них. Они примеряют на себя образ «защитника, спасателя, героя», т.к. носители проблемы не способны самостоятельно выйти из сложившейся ситуации. Им необходим кто-то, кто выдвинет от их имени требования, возьмет на себя ответственность, которая будет выходить за пределы личных интересов. Подобная тематика проходит лейтмотивом описания деятельности: «Хочется рассказывать про путь героя, а не про жалкую сиротку» (Д.А., 
Теории и практики 2020), «Бизнес- это такая большая ответственность... Ты живешь бизнесом 24 часа в сутки» (Г. С, Inc. 2019). Лейтмотив «спасателя» усиливается гражданским стилем выдвижения утверждений-требований, который предполагает моральное возмущение. Иногда продвижение образа порядочного человека, который пытается всеми силами сделать мир лучше, имеет негативные последствия: «Все, что я рассказывала о нашей работе и чем гордилась, обратили против нас. В такие моменты важны поддержка общества и награды, т.к. это защищиает нас от нападок и легитимизирует нашу деятельность» (Д.А., Rusbase 2018). Речь идет о скандале вокруг бизнеса, связанном с открытием прачечной для бездомных, которую Дарья Алексеева хотела открыть совместно с организацией «Ночлежка». Местные жители противостояли этой инициативе.

Общий позитивный настрой на демонстрацию всего самого положительного прослеживается в каждом интервью Гузели Санжаповой. Местные жители называются только как «бабушки», «дедушки», а сама предпринимательница- как «любимая внучка для всех». Демонстрация уникальности, неповторимости сельской жизни осуществляется через знакомство с сельским бытом и противопоставление его городскому образу жизни:

Раз в неделю туда приезжает автолавка с продуктами, в которой жители покупают хлеб на неделю вперед. Для нас- тех, кто живет в городе,это за гранью, а в деревне это просто реальность... Обычная практика для деревни - долговые книги, куда люди записывают покупки в долг. Когда деньги появляются, долг возвращают. Больше долговых книг в Малом Турыше нет (Г. С., Афиша Daily 2018).

Второй используемый прием в рамках данной риторики утраты-это романтизация сельской жизни: «комфортная жизнь в деревне», «люди, заботливо собирающие каждую ягодку», «устроить вечеринку с бабушками», «бабушки собираются вместе и толпой идут до соседней деревни и обратно, просто гуляют», «счастливые лица жителей».

Риторика наделения правом используется тогда, когда стремятся подчеркнуть значимость доступа всех к выбору самовыражения и свободы самореализации в рамках выбора. Словарь риторики также содержит негативные термины, такие как нетерпимость, угнетение, сексизм, расизм, эйджизм, и позитивные термины: жизненный стиль, различия, выбор, терпимость, мультикультурный, предоставление возможностей (Ибарра, Китсьюз 2007: 77). В активном словаре социальных предпринимателей и в рамках данной риторической идиомы используются только позитивные термины, включая центральный термин «расширение» благ/услуг/прав и принципы честной игры (терпимость, справедливость, уважение человеческого достоинства):

Мы показываем, что у пожилых есть возможность быть такими же молодыми, как мы, развлекаться так же, как мы, петь песни и отжигать по полной. Иногда я собираю всех жителей, чтобы поговорить о будущем 
деревни и выслушать их... Они рассказывают мне свои самые смелые мечты. $<$. . > Раньше < ..> бабушки стеснялись и прятали лица от камер... Сегодня смело обо всем рассказывают и гордятся собой (Г.С., Теплица социальных технологий 2018; Афиша Daily 2018).

Дарья Алексеева использует риторику наделения правом при описании такого направления своей деятельности, как трудоустройство социально незащищенных слоев населения: «Mы не тратим на это дополнительные деньги, просто не нанимаем сотрудников с hh.ru, а стараемся дать возможность тем, для кого эта работа- ианс что-то изменить в своей жизни» (Д. А., Rusbase 2018).

Дальнейшее погружение в тонкости риторики дискурса выявило отличительную особенность социальных предпринимателей от других акторов легитимации социальных проблем. Социальные предприниматели в публичном дискурсе в меньшей степени драматизируют саму проблему, а в большей степени характеризуют и популяризируют свой способ решения данной проблемы:

Это как бы такой позитивный взгляд на проблему: да, она существует, но мы сейчас скажем, что нужно сделать, и покажем, как именно ситуация изменится к лучшему, если уже прямо сейчас предпринять конкретные действия. Вне зависимости от качества [сданной] одежды происходит что-то хорошее: либо мы отдаем вещи на благотворительность, либо продаем, либо перерабатываем... Это возможность что-то менять, создавать какие-то ценности (Д. А., Сколково 2020).

Позитивность предложенного решения на контрасте с негативизмом самой проблемы- это тоже своеобразный риторический прием в публичном дискурсе социальных предпринимателей, который отражает особенности их деятельности как акторов социальной политики- осуществление реальных действий в тех сферах, с той группой, которые остаются за пределами интересов других агентов социальной политики. Эта позиция позволяет сделать вывод, что выбранные нами социальные предприниматели, согласно типологии Шэйкера Захры (Zahra et al. 2009), выполняют роль «социальных конструкционистов». Типология основывается на способах решения социальной проблемы, исходя из возможностей и приоритетов деятельности социальных предпринимателей, и включает в себя помимо социальных конструкционистов еще социальных «бриколеров» (мастера на все руки) и социальных инженеров. Цель деятельности социальных конструкционистов (Ibid:525-526) - это разработка и внедрение альтернативных способов решения социальных проблем в тех сферах, где государство, учреждения социального обслуживания и бизнес не могут удовлетворить социальные потребности целевой аудитории. Они обосновывают свою деятельность тем, что существующие, общепризнанные способы решения социальных проблем существенно ограничиваются законодательством, приоритетными направлениями социальной политики, 
экономической и политической ситуацией в стране. Поэтому действующие государственные организации и бизнес-структуры не могут эффективно удовлетворять многие важные социальные потребности целевой аудитории, а социальные предприниматели данного типа решают острые социальные проблемы в существующем контексте и помогают поддерживать гармонию. Данная позиция напрямую влияет на особенности риторики дискурса социальных предпринимателей.

\section{Заключение}

Риторическая деконструкция публичного дискурса двух успешных российских социальных предпринимательниц показывает, что данные акторы актуализируют социальные проблемы только посредством положительных словарей риторик утраты и наделения правом вне зависимости от географии деятельности и используемой бизнес-модели. Разница заключается только в тех условиях-категориях, которыми они типизируют свою деятельность. Гузель Санжапова артикулирует необходимость возрождения малых деревень, а Дарья Алексеева-экопотребление. Но, как показал наш анализ, условия-категории в меньшей степени определяют доминирующий контекст риторики социальных предпринимателей как агентов социальных изменений. Центральными, объединяющими элементами являются общий лейтмотив и характер публичных выступлений. Лейтмотив «защитника, спасателя, героя» и гражданский стиль выдвижения утверждений-требований повышают доверие населения к социальным предпринимателям как игрокам современного рынка социальных услуг и активным спикерам на публичных аренах легитимации социальных проблем. Наше исследование позволило также выделить отличительные особенности стратегии мобилизации действий, предлагаемой социальными предпринимателями для решения социальной проблемы, которая акцентирует внимание на готовых вариантах решения, вместо драматизации проблемной ситуации.

Учитывая все вышесказанное, выступления социальных предпринимателей на публичных аренах с целью продвижения социальной миссии можно рассматривать и как процесс легитимации социальных проблем общества с выделением особой стратегии легитимации «от проблемы к решению», позволяющей рассматривать социальных предпринимателей как перспективных агентов социальных изменений. Таким образом, наше исследование демонстрирует, что концепция Ибарры и Китсьюза обладает большим потенциалом в изучении риторики дискурса социальных предпринимателей, систематический и детальный анализ которой позволит выделить траектории легитимации самого социального предпринимательства как нового игрока в сфере социальной политики. Перспективным направлением дальнейших исследований может выступать дискурсивный анализ риторики социальных предпринимателей других типов, согласно 
типологии Захры. Подобное исследование позволило бы понять, являются ли выявленные риторические приемы универсальными для всех социальных предпринимателей как акторов социальной политики или нет.

\section{Выражение признательности}

Исследование осуществлено в СПбГУ при поддержке РНФ, проект «Вызовы трансформации социального государства в России: институциональные изменения, социальное инвестирование, цифровизация социальных услуг» № 19-18-00246.

Редакция благодарит программу Университетское партнерство за поддержку и возможность опубликовать данную статью.

\section{Материалы для анализа}

Афиша Daily (2017) Почему нам всем пора избавиться от лишней одежды. Доступно по ссылке: https:/daily.afisha.ru/relationship/7165-pochemu-nam-vsem-pora-izbavitsya-otnenuzhnoy-odezhdy/ (дата обращения: 16 февраля 2021).

Афиша Daily (2018) Как производство крем-меда спасает глухую деревню: история Малого Турыша. Доступно по ссылке: https://aily.afisha.ru/cities/8763-kak-proizvodstvo-krem-medaspasaet-gluhuyu-derevnyu-istoriya-malogo-turysha/ (дата обращения: 16 февраля 2021).

Правила игры (2017) Гузель Санжапова- соииальный предприниматель. Доступно по ссылке: https://rulesplay.ru/articles/sotsialnoe-predprinimatelstvo-dver-voydya-v-kotoruyuobratno-ne-verneshsya/ (дата обращения: 16 февраля 2021).

Сколково (2020) Истории успеха: Алексеева Дарья. Доступно по ссылке: https://alumni. skolkovo.ru/content_page/item/79-successstory-alekseeva/ (дата обращения: 16 февраля 2021). Теории и практики (2020) Основательнииа Charity Shop Даша Алексеева: «Строгость нужна, иначе человек будет отправлять PDF вверх ногами». Доступно по ссылке: https:// theoryandpractice.ru/posts/16969-osnovatelnitsa-charity-shop-i-fonda-vtoroe-dykhanie-dashaalekseeva-strogost-nuzhna-inache-chelovek-budet-otpravlyat-pfd-fayly-vverkh-nogami (дата обращения: 16 февраля 2021).

Теплица социальных технологий (2018) Гузель Санжапова: «Краудфандинг- это не о проблеме, это о ее решении». Доступно по ссылке: https://te-st.ru/2018/04/03/cocco-bello-honeycrowdfunding/ (дата обращения: 16 февраля 2021).

Типичная Москва (2018) Интервью с основательницей проекта Charity shop Дарьей Алексеевой. Или о том, почему тяжело продать туфли Ренаты Литвиновой. Доступно по ссылке: https://typical-moscow.ru/intervyu-charity-shop/ (дата обращения: 16 февраля 2021).

Inc. (2019) Чего я не знала, начиная бизнес: Гузель Санжапова, основательница Соссо Bello Нопеу. Доступно по ссылке: https://incrussia.ru/understand/chego-ya-ne-znala-nachinayabiznes-guzel-sanzhapova-osnovatelnitsa-cocco-bello-honey/ (дата обращения: 16 февраля 2021).

Rusbase (2018) «Многим кажется, что мой бизнес- золотая жила. На самом деле-нет». Как Дарья Алексеева хакнула традиционную модель секонд-хенда. Доступно по ссылке: https://rb.ru/longread/charityshop/ (дата обращения: 16 февраля 2021).

\section{Список источников}

Бест Дж. (2007) Социальные проблемы. И.Г. Ясавеев (ред.) Социальные проблемы: конструкиионистское прочтение. Казань: Издательство Казанского университета: $26-54$. 
Ибарра П., Китсьюз Дж. (2007) Дискурс выдвижения утверждений-требований и просторечные ресурсы. И.Г. Ясавеев (ред.) Сочиальные проблемы: конструкционистское прочтение. Казань: Издательство Казанского университета: 55-114.

Кольцова О. Ю., Ясавеев И. Г. (2013) Конструирование проблемы полицейского насилия в российской блогосфере: риторика, лейтмотивы и стили. Журнал соичологии и социальной антропологии, 16 (3): 81-100.

Полач Д. (2010) Социальные проблемы с конструкционистской точки зрения. Журнал исследований социальной политики, 8 (1): 7-12.

Хилгартнер С., Боск Ч. (2007) Рост и упадок социальных проблем: концепция публичных арен. И.Г. Ясавеев (ред.) Социальные проблемы: конструкиионистское прочтение. Казань: Издательство Казанского университета: 145-184.

Ясавеев И.Г. (2004) Конструирование социальных проблем средствами массовой коммуникации. Казань: Издательство Казанского университета.

Ясавеев И.Г. (2016) Риторика контролируемого бедствия: специфика конструирования ФСКН проблемы потребления наркотиков. Журнал исследований соииальной политики, 14 (1):7-22.

Ясавеев И.Г. (2019) ВИЧ/СПИД в России: властная и активистская конструкции социальной проблемы. Социологическое обозрение, 18 (3): 49-76.

Becker H. S. (ed.) (1966) Social Problems: A Modern Approach. New York: John Wiley and Sons.

Blumer H. (1971) Social Problems as Collective Behavior. Social problems, 18 (3): 298-306.

Dees J. G., Anderson B. B. (2006) Framing a Theory of Social Entrepreneurship: Building on Two Schools of Practice and Thought. Research on Social Entrepreneurship. ARNOVA Occasional Paper Series, 1 (3): 39-66.

Defourny J., Nyssens M. (2010) Conceptions of Social Enterprise and Social Entrepreneurship in Europe and the United States: Convergences and. Journal of Social Entrepreneurship, 1 (1): 32-53.

Ibarra P. R., Kitsuse J. I. (2003) Claims-making Discourse and Vernacular Resources. In: G. Miller, J. A. Holstein (eds.) Challenges and Choices: Constructionist Perspectives on Social Problems. New York: Aldine de Gruyter: 17-50.

Loseke D. R. (2003) Thinking about Social Problems: an Introduction to Constructionist Perspectives. New York: Aldine de Gruyter.

Salamon L. M. (1997) Holding the Center: America's Nonprofit Sector at the Crossroads. New York: Cummings Foundation.

Spector M., Kitsuse J. I. (1977) Constructing Social Problems. Menlo Park, CA.: Cummings.

Zahra S. A., Gedajlovic E., Neubaumc D. O., Shulmand J.M (2009) A Typology of Social Entrepreneurs: Motives, Search Processes and Ethical Challenges. Journal of Business Venturing, 24 (5): 519-532. 
Elena Arkhipova, Alevtina Starshinova

\section{FROM PROBLEM TO SOLUTION: THE RHETORIC OF THE DISCOURSE OF SOCIAL ENTREPRENEURS}

This article presents the result of analysis of the discourse of modern social entrepreneurs as actors in the legitimation of social problems of society. Based on the ideas of a constructionist approach, we considered social problems not as an objective reality in society, but as a construct of claimsmaking to change a situation created by people. Recent studies show the low effectiveness of measures used by 'insiders' of social policy. Social entrepreneurs, being new actors in the process of advancing and legitimizing social problems, according to the authors, have high potential not only in constructing a social problem, but also in developing its effective solution. The empirical basis of the study was public speaking, interviews, and descriptions of projects presented on official websites, crowd platforms and social networks of leaders of Russian social entrepreneurship Guzel Sanzhapova (Maly Turysh village, Sverdlovsk region) and Daria Alekseeva (Charity Shop, Moscow). Both entrepreneurs are actively involved in the discourse of social problems, formulate claims-making and promote them in public arenas. In our analysis we use the concept of Peter Ibarra and John Kitsuse, which measures the discourse of social problems in four dimensions of rhetoric: rhetorical idioms, counter-rhetoric, motifs and claims-making styles. The study showed that social entrepreneurs on the public arena do not use negative and dramatic rhetorical idioms, such as the rhetoric of endangerment, unreason and calamity. There are rhetoric of loss and rhetoric of entitlement. We conclude that social entrepreneurs play the role of 'social constructivists' (according to the Shaker Zahra typology), filling social gaps, solving acute social problems, working in those areas and with those groups that remain beyond the interests of other agents of social policy.

Keywords: social entrepreneurship, social problems, constructionism, rhetoric, discourse

DOI: 10.17323/727-0634-2021-19-1-41-54

\section{Acknowledgments}

This article was carried out with support of the Russian Science Foundation (RSF) according to scientific project no. 19-18-00246 'Challenges of Transformation of the Welfare State in Russia: Institutional Changes, Social Investment, Digitalization of Social Services,' implemented at Saint Petersburg State University.

Elena B. Arkhipova-Cand. Sci. (Soc.), Associate Professor, Department of Social Work, Ural Federal University, Ekaterinburg, Russian Federation. Email: e.b.arkhipova@urfu.ru

Alevtina V. Starshinova- Dr. Sci. (Soc.), Professor, Department of Social Work, Ural Federal University, Ekaterinburg, Russian Federation. Email: a.v.starshinova@urfu.ru 


\section{References}

Becker H.S. (ed.) (1966) Social Problems: A Modern Approach. New York: John Wiley and Sons.

Best J. (2007) Sotsial'nye problem [Social Problems]. In: I. G. Yasaveev (ed.) Sotsial'nye problemy: konstruktsionistskoe prochtenie [Social Problems: A Constructionist Reading]. Kazan': Izdatel'stvo Kazanskogo universiteta: 26-54.

Blumer H. (1971) Social Problems as Collective Behavior. Social problems, 18 (3): 298-306.

Dees J.G., Anderson B. B. (2006) Framing a Theory of Social Entrepreneurship: Building on Two Schools of Practice and Thought. Research on Social Entrepreneurship. ARNOVA Occasional Paper Series, 1 (3): 39-66.

Defourny J., Nyssens M. (2010) Conceptions of Social Enterprise and Social Entrepreneurship in Europe and the United States: Convergences and. Journal of Social Entrepreneurship, 1 (1):32-53.

Hilgartner S., Bosk Ch. (2007) Rost i upadok sotsial'nykh problem: kontseptsiya publichnykh aren [The Rise and Decline of Social Problems: the Concept of Public Frenas]. In: I. G. Yasaveev (ed.) Sotsial'nye problemy: konstruktsionistskoe prochtenie [Social Problems: A Constructionist Reading]. Kazan': Izdatel'stvo Kazanskogo universiteta: 145-184.

Ibarra P. R., Kitsuse J. I. (2003) Claims-making Discourse and Vernacular Resources. In: G. Miller, J. A. Holstein (eds.) Challenges and Choices: Constructionist Perspectives on Social Problems. New York: Aldine de Gruyter: $17-50$.

Ibarra P., Kitsuse J (2007) Diskurs vydvizheniya utverzhdeniy-trebovaniy i prostorechnye resursy [Claims-making Discourse and Vernacular Resources]. In: I.G. Yasaveev (ed.) Sotsial'nye problemy: konstruktsionistskoe prochtenie [Social Problems: A Constructionist Reading]. Kazan': Izdatel'stvo Kazanskogo universiteta:55-114.

Kol'tsova O. Yu., Yasaveev I.G. (2013) Konstruirovanie problemy politseyskogo nasiliya v rossiyskoy blogosfere: ritorika, leytmotivy i stili [Constructing the Problem of Policy Violence in the Russian Blogosphere: Rhetoric, Motifs and Claims-Making Styles]. Zhurnal sotsiologii i sotsial'noy antropologii [The Journal of Sociology and Social Anthropology], 16 (3): 81-100.

Loseke D. R. (2003) Thinking about Social Problems: an Introduction to Constructionist Perspectives. New York: Aldine de Gruyter.

Pawluch D. (2010) Sotsial'nye problemy s konstruktsionistskoy tochki zreniya [Social Problems in Constructionist Terms]. Zhurnal Issledovanii Sotsial'noi Politiki [The Journal of Social Policy Studies], 8 (1): 7-12.

Salamon L. M. (1997) Holding the Center: America's Nonprofit Sector at the Crossroads. N.Y.: Cummings Foundation.

Spector M., Kitsuse J. I. (1977) Constructing Social Problems. Menlo Park, CA: Cummings.

Yasaveev I. G. (2004) Konstruirovanie sotsial'nykh problem sredstvami massovoy kommunikatsii [The Construction of Social Problems by Mass Communication]. Kazan': Izdatel'stvo Kazanskogo universiteta.

Yasaveev I. G. (2016) Ritorika kontroliruemogo bedstviya: spetsifika konstruirovaniya FSKN problemy potrebleniya narkotikov [Controlled Disaster Rhetoric: The Specificity of the Construction of the FSK Drug Use Problem]. Zhurnal Issledovanii Sotsial'noi Politiki [The Journal of Social Policy Studies], 14 (1): 7-22.

Yasaveev I. (2019) VICh/SPID v Rossii: vlastnaya i aktivistskaya konstruktsii sotsial'noy problem [HIV/AIDS in Russia: the Imperious and Activist Constructs of the Social Problem]. Sotsiologicheskoe obozrenie [Russian Sociological Review], 18 (3):49-76.

Zahra S. A., Gedajlovic E., Neubaumc D. O., Shulmand J.M (2009) A Typology of Social Entrepreneurs: Motives, Search Processes and Ethical Challenges. Journal of Business Venturing, 24 (5): 519-532. 